\title{
Semantic Primes in Political Communication: Hillary Clinton and Donald Trump Final Presidential Debate
}

\author{
Sara El-Daly, Department of English, University of Menofia, Faculty of \\ Arts \\ Correspondence concerning this article should be addressed to Sara El- \\ Daly, English Department, Menofia University, E-mail: \\ Saraseldaly12@gmail.com.
}

\begin{abstract}
This paper is conducted within the framework of critical discourse analysis as it aims at investigating the lexical semantic primes that are represented in the last political debate between Hillary Clinton and Donald Trump. The universal primes belong to what is known as the 'Natural Semantic Meta-language' (NSM). The main aim of this theory is to reduce the semantics of all lexicons to a limited set of words/semantic primitives. This theory deals mainly with language, cognition, and culture. Therefore, the semantic primes used in the political debate display the linguistic strategies employed by the candidates. They play the role of describing, then interpreting the meaning transferred through the process of communication. Moreover, these semantic primes reflect a degree of intensity of information (in a simple way) either in speech or written text. The extent to which each candidate tries to impress, by focusing on linguistic devices, the listeners/readers of the debate, lexical density (the ratio between function to content words) is investigated to reflect the intensity of information represented in the debate.
\end{abstract}

Keywords: Presidential debates, political communication, semantic primes, information intensity

\section{Theoretical Background and Statement of the Problem}

Frequently, presidential debates refer to a type of political discourse where a political communicative situation is described and presented. Political discourse is 'a class of genre defined by a social domain' (van Dijk, 2002, P.19). He adds that political discourse is ideological since it displays the candidates' personal beliefs and views. In presidential debates, the candidates representing two different programs try to represent their political directions through language. The rhetorical devices that are performed in political debates aim at affecting people who are watching, listening, or reading them. Thus presidential debates represent an essential medium for information transfer.

The process of reception and perception of the information is seen when experiencing the 'information' through the process of communication. Experience indicates the interactants' complete awareness of all the factors surrounding the situations. Moreover, it displays their abilities to transfer this experience in different group/s employing a variety of 
strategies. The reception, perception, and experiencing knowledge (of information) with others are managed in discourse processing; K-device (Van Dijk, 2005, p.76) that is the tool that reflects knowledge in light of 'context'. The context factor is derived from van Dijk's (2006, p. 170) 'context model', "the mental representation of the participants in the social situation in which participants interact, produce, and comprehend text or talk". So, speech producers should manage knowledge strategic transmission processes. The strategies of knowledge transmission processes lie in the macro/micro analysis of the given speech in a particular speech event where the relationship between the ideas and its meaning reflects the ideology of its producers. The investigation of discourse semantic choices of phrasing and structuring helps to see how the levels of language performance, along with the discursive practices either in/out the group, may affect the system of belief of the intended group locally and/or globally.

Politically speaking, presidential debates represent an important political activity, because it helps voters to evaluate and to decide the appropriate candidate. Their preference depends on the candidates' campaigns representation for these reasons: the presidential debates reveal the candidates' ability to interact with others; 2) the candidates' ability to manage the opponent and persuade the voters or remain passive; and 3) the candidates' self-image (political ideology) through a) argumentative rhetorical language and/or b) non-verbal behavior towards the opponent (polite/offensive) (Prace, 2013, p. 16).

Previous research has suggested that the United States of America has witnessed two main periods of the presidential debates, the LincolnDouglas era that gained a remarkable interest at that time, and the mediaoriented debates, starting with Harold Stassen and Thomas Dewey via radio broadcasting then the televised famous Kennedy and Nixon debate (Napierala, 2014, p. 127-128).

As for the genre of these debates, the political debates are basically 'comparative'. They display the political campaign (designed program) of the elected candidates. Consequently, they are highly argumentative as each of the candidates try to prove being credential to the voters. Trying to affect people depends on the rhetorical linguistic features, paralinguistic cues employed by the politicians, and following the debates' regulations also requires due concern. The presidential debates reflect the candidates' ideological consideration through the debate's nature, format, and content. The nature and format present the activities designed by the campaign team and performed by the candidates while the audience is 


\section{Sara El-Daly}

watching (Boyd, 2013. p, 300). The content of the debates contain all the non/verbal communication tools that help the candidates convey their message and/or affect their people.

Given its political origin, presidential debates perform many functions. The debate functions are achieved when it is well-established to depict both the policy and the character (self-image) of the candidate (Benoit and Hansen, 2004, P. 126). The candidates employ both the linguistic tools (e.g. lexicalization, metaphors, metonymy, and ironical stances among others) and the non-verbal devices to reflect the im/polite behavior. Briefly, the functions, in Figure 1 are regarded as format components in this study, mentioned in (Napierala, 2014, p. 127) are:

1. Acclaims; these are the moves that are related to the contextual situation;

2. Attacks; these moves are used to affect the voters' evaluation of the opponent; finally

3. Defending; establishing self-image depending on the selected strategy to respond to attacks.

Recent studies have displayed a due interest in the area of political communication such as (Rashidi and Souzandehfar, 2010; Nozickova, 2013; Napierala, 2014; and Savoy (2016) have examined the presidential debates in the US context. Both Rashidi and Souzandehfar (2010) and Nozickova (2013) have used CDA as a tool to examine the positive-self representation and negative-other representation, in addition to the ideological square categorization. The researchers have found that the candidates depend mainly on non-verbal communication, argumentative language, and polite/offensive behavior towards the other candidates, in addition to, employing the ideological square to affect people.

It must be noted that the US presidential debate examination presented by Napierala (2014) displays more about the US debates' nature. After giving a historical background of the US presidential debates and the verbal strategies followed by the candidates to display their programs, Napierala has focused on the two American candidates: Barack Obama and John McCain. She has found that the politicians are trained how to speak in different situations (P. 136); Obama has used the verbal debate strategies more to reflect his leadership experience.

Furthermore, a more recent rhetorical analytical study that addresses the rhetorical style during the 2016 presidential debates of Trump and Clinton is investigated by Savoy (2016). The speech delivered represents 
the written communication genre. The corpus of this study is divided into parts; the first set of documents is the twelve televised Republican's debates and nine debates for the Democrats. The second set of documents is derived from the three presidential debates. This kind of data is completely different from the televised debates of the two political parties. The third set of documents is the written communication; 37 speeches uttered by Clinton and 58 given by Trump. The analysis starts with word occurrence frequencies. Savoy found that the most frequent morphological word is 'the' and 'verb to be'. The personal pronoun 'I and we' appear relatively high. The information intensity is measured by lexical density, to see the ratio of the content and functional words. The researcher found that Trump uses more functional words while Clinton provides more information (lexical and content words). The general conclusion shows that Trump's general oral genre style is simple, direct, using short sentences and words are easy to understand, repeated through the text (P.8). However, his general written genre style is characterized by richer expressions, formulations, more complex lexical choices, and fewer instances of repetition. Trump's oral form of verbs is slightly oriented towards action through verbs and adverbs while Clinton is oriented towards more descriptive rhetoric (nouns, adjectives, and determiners) (P. 18)

The previously mentioned research reflects that there is a lot of research that is done in the area of political communication. However, less interest is given to the relation between semantic primes and information intensity through lexical density in the final 2016 US presidential debate. Therefore, this study aims at examining the candidates' use of semantic primes as linguistic carriers of meaning and information in the last USA presidential debate. The critical question now is about the extent to which semantic primes affect displaying and conveying information among different groups of people.

\section{The Present Study}

\subsection{Aim of the Study}

This study is undertaken to examine the information intensity distribution across the polemical interactional exchanges in the last US presidential debate between Hillary Clinton and Donald Trump. The information intensity is measured by focus on semantic primes' along the questions discussed in the presidential debate. The nature of distributed information by each candidate and the nature of difference between both of them is also one of the reasons the study is conducted. Therefore, the study proposes the following questions: (1). How are semantic primes employed in the last Presidential debate? ; (1A) Where are the semantic 


\section{Sara El-Daly}

primes highly employed?; (2) Do semantic primes help to achieve the presidential debates' functions?; (3) How has 'lexical density' been achieved clearly through semantic primes?

\section{Semantic Primitives in Communication (Semantic Primes/SPs)}

Semantics is concerned with the meaning of words/utterances said in various interactional speech communities. The discursive practices display different cultural scripts (i.e., different cultures, and different languages, different speech acts) (Wierzbicka, 2010, P. 46). Cultural scripts in a simple way refer to the process of coding and decoding of the communication message to approach the highest social values that are expressed in various situations.

Human interaction reveals two modes of language use in communication: the simple and the complex. The complex mode in communication results from the use of 'academic English forms' that may have not any counterparts in any other languages and societies (Wierzbicka, 2003, p.4), while the simple mode of communication derives from the notion that all the languages are simple and universal or near-universal, and share common ground. Given the notion of universality and simplicity, SPs refer to the use of such simple and common lexemes as displayed in Table 1: "I", "you", "want", "need", "something", "this ", "thing", "good", and "bad". So, the simple sentences may be used in different ways to render the meaning of "I want this thing", "someone wants you", "I did so", "something happened there", and "this is a good/bad thing". These lexemes are known as the semantic primitives of the language. These semantic primitives belong to what is known as Natural Semantic Metalanguage (henceforth, NSM) (P.4). They are presented in the following table.

\section{Table 1}

\section{Semantic primes}

\begin{tabular}{|l|l|}
\hline Substantives: & $\begin{array}{l}\text { I, you, someone, something/thing, people, } \\
\text { body }\end{array}$ \\
\hline Relational substantives: & Kind, part \\
\hline Determiners: & this, the same, other/else \\
\hline Quantifiers: & One, two, much/many, some, all \\
\hline Evaluators: & Good, bad \\
\hline Descriptors: & Big, small \\
\hline Mental predicates: & think, know, want, feel, see, hear \\
\hline Speech: & say, words, true \\
\hline $\begin{array}{l}\text { Action, events, movement, } \\
\text { contact: }\end{array}$ & do, happen, move, touch \\
\hline
\end{tabular}




\begin{tabular}{|l|l|}
\hline Substantives: & $\begin{array}{l}\text { I, you, someone, something/thing, people, } \\
\text { body }\end{array}$ \\
\hline $\begin{array}{l}\text { Location, existence, } \\
\text { possession, specification: }\end{array}$ & $\begin{array}{l}\text { Be (somewhere), there is/exist, have, be } \\
\text { (someone/something) }\end{array}$ \\
\hline Life and death: & Live, die \\
\hline Time: & $\begin{array}{l}\text { When/time, now, before, after, a long time, } \\
\text { a short time } \\
\text { For some time, moment }\end{array}$ \\
\hline Space: & $\begin{array}{l}\text { Where/place, here, above, below, far, near, } \\
\text { side, inside }\end{array}$ \\
\hline Logical concepts: & not, maybe, can, because, if \\
\hline Augmentor, intensifier: & very, more \\
\hline Similarity: & Like/as \\
\hline
\end{tabular}

Furthermore, NSM is an approach for examining the meanings and ideas of any natural language. Its main claim stems from the premise that all natural languages share a common core and a universal grammar and a small set of conceptual primes (simple lexicons) (Wierzbicka, 1985). Firstly, simple use of language is derived from its linguistic conceptualized basics. The 'simplicity' is shown across the use of small set of lexicons (P.49) that differs from one person to another according to the socio-cultural and contextual features that affect the whole speech event. Secondly, the universality of language depends mainly on its 'syntactic structures' as Wierzbicka (1996) proceeds "the universal syntax of meaning consists of universal combinations of universal conceptual primitives" (p. 20).

According to its basic notions of simplicity and universality, semantic primes' use in different situational events indicates that the speech/text can be easily decoded and further communicated, the use of semantic primes (i.e. small set of meaningful lexicons) enhances the process of inter/intra cultural communication as facilitating the information transfer process. The primitives' use reduces the focus on the formal English and allows the appearance of a new way of interpreting and understanding the communicative message. In this sense, English is treated in a simple way rather than the syntactical formal way. Thus, it will get much help to language learners, children and immigrants (Goddard, 2010. p. 50).

"Why semantic primes?" is the question that arises now. Given that 'semantic primes' stem from lexical semantics; it extends itself to focus on the illocutionary semantics and grammar (Goddard, 2010, p. 4 and Kalisz, 1993, p. 116). 'Illocutionary force' is driven from the pragmatic division 


\section{Sara El-Daly}

of any utterance into acts (Searle, 1975, p. 59-62). So, the readers/listeners of a written/spoken discourse have to infer the implicit meaning of any given discourse (when found). These inferences are the result of activating a large amount of knowledge in the memory of the readers/listeners that leads them to understand the written/spoken sentence in a way that combines both their old retained knowledge and the new acquired knowledge.

In a series of research studies, semantic primes have been examined to figure out their universality (Joo Yoon, 2001); and their simplicity (Swan, 2013; MateoMendaza, 2016; Goddard and Wierzbicka (2007). Moreover, semantic primes have proved to be utilized in language teaching, education, and international communication as well (Goddard and Wierzbicka, 2007). However, it is obvious that there have been no adequate conducted studies on political discourse (i.e. presidential debates) and semantic primes.

\subsection{Methods and Procedures}

\subsubsection{Data}

The database of this study is the transcript of the candidates' speech in the third and last presidential debate of the USA for 2016. This debate took place at the University of Nevada, Las Vegas. There are six issues with six questions discussed in the debate. The topics and the questions are designed by the interviewer. The candidates answered according to particular rules because both the campaigns have agreed to those rules. The transcript was taken from the Internet from the Washington Post (WP Company (US), retrieved from https://www.washingtonpost.com/. The candidates were given limited time to answer the questions. The two candidates represent two opposing parties; Hillary Clinton represents the Democratic Party and Donald Trump represents the Republican Party. Moreover, this debate is sponsored by the Commission on Presidential Debates. Table 1 shows the main/secondary initiated issues in the last debate.

Table 2

The issues discussed across the two speeches

\begin{tabular}{|l|}
\hline \multicolumn{2}{|c|}{ Issues discussed across the two speeches } \\
\hline 1-The National security; Supreme Court, Second \\
Amendment, and Guns \\
\hline 2-The foreign policy; the borders and immigrants, ISIS, \\
Syrian/Iraqi relations issue and Russian relations. \\
\hline 3-Economy; taxes and jobs, trade deals and national debt. \\
\hline
\end{tabular}




\begin{tabular}{l} 
4-Clinton's Scandals; WikiLeaks and ISIS. \\
\hline 5-Trump's Scandals; treatment of women \\
\hline 6- Fitness to be a president; e-mails for money transfer to \\
her private account, Haiti Foundation and peaceful \\
transition of power.
\end{tabular}

\subsubsection{Framework of Analysis}

The framework of analysis is a discourse NSM approach on the base of critical discourse analysis. The critical discourse ideological square and self representation (van Dijk, 2006, p. 734) and NSM method of analysis (Goddard, 1996 and 2010) are combined to fully interpret the examined data. Concerning the semantic primes, they are regarded as the core of language meaning (Goddard, 2006, p. 2). For the purpose of the study, the primes are divided by the researcher into function and content words to measure the 'lexical density/LD' (Paltridge, 2006, p.14) across the presidential debate three main functions; acclaims, attacks, and defending. This division is stated in the following table.

\section{Table 3}

Function and Content Semantic Primes

\begin{tabular}{|l|l|}
\hline $\begin{array}{l}\text { Function Semantic } \\
\text { Primes/FSP }\end{array}$ & $\begin{array}{l}\text { Content Semantic } \\
\text { Primes/CSP }\end{array}$ \\
\hline Substantives & Evaluators \\
\hline Relational substantives & Descriptors \\
\hline Determiners & Mental Predicators \\
\hline Quantifiers & Speech \\
\hline Location/existence & $\begin{array}{l}\text { Actions, } \\
\text { Movements }\end{array}$ \\
\hline Possession, specification & Life, death \\
\hline Time & Logical concepts \\
\hline Space & \\
\hline Augmenter/intensifier & \\
\hline Similarity & \\
\hline
\end{tabular}

Concerning van Dijk's (2006, p. 735-739) 'ideological square', he shows that there are some linguistic features employed by the participants in a political speech event. These features build the 'ideology' of the speaker. These features are; a) actor description refers to the way the actors or members are described; b) categorizing reflects the categorization of people in different groups; c) disclaimer is the use of the logical 'but' to introduce a new idea; d) evidentiality is the way followed to prove an idea 
by using facts and statistics; e) hyperbole is used to show up the exaggerating meaning; f) implication refers to inferring implicit information; g) irony is seen across saying something and meaning another one; finally, h) lexicalization is used to represent the negative other-representation ideological strategy through semantic words (adopted from Rashidi and Souzandehfar, 2010, p. 69-70).

\subsubsection{Procedure of Analysis}

In order to analyze the written transcript of the presidential debate, firstly, the debate is divided into two extracts; each one belongs to the candidate's speech. Secondly, the transcript of each candidate is divided according to topics/questions discussed, and each utterance/transcribed text is given a number in relation to the debate's parts. Thirdly, the semantic primes are identified and counted to see the frequency of occurrence of each category. Finally, the SPs are divided into function and content words to examine the 'lexical density' (Paltridge, 2006, p. 14$15)$; the frequency of occurrence along with the semantic primes' division is presented in tables in the next section.

\section{Results and Discussion}

\subsection{The Three Presidential Debate Functions}

Johnstone (2002) states that ' Discourse shapes possible purposes and is shaped by purpose' (p. 17). This indicates that the linguistic choices the candidates employ aim at achieving certain purposes: persuasion, ideology reflection and election decision. Therefore, the pre-determined presidential functions employed and achieved in the presidential debate are fulfilled with the help of SPs. The relation between content and functional SPs and these functions is indispensable. The most preferred functions in the final presidential debate are shown in the following table:

\section{Table 4}

The Preference of Clinton's and Trump's employed Functions

\begin{tabular}{|l|l|l|}
\hline Debate Functions & Clinton & Trump \\
\hline Acclaims & $\begin{array}{l}17 ; 16 \text { policy, 1 } \\
\text { character }\end{array}$ & 14 policy \\
\hline Defending & 13 policy & 4 policy \\
\hline Attacks & $\begin{array}{l}8: 7 \text { policy, 1 } \\
\text { character }\end{array}$ & $\begin{array}{l}16 ; 15 \text { policy, 1 } \\
\text { character }\end{array}$ \\
\hline
\end{tabular}

It is clear that the two candidates use the three functions of the presidential debate in a different way. Clinton makes use of acclaims and defending more than attacks. Conversely, Trump depends on attacks and acclaims rather than defending. Each of these functions shows the candidates' strategy in displaying his/her own program shedding light on the past or future deeds. One of the reasons that affects structuring this 
debate is the political background of the two candidates. Due to Clinton's political background, she has selected 'acclaim' mostly to refer to her past and future deeds.

Generally speaking, the use of 'acclaim' either for 'policy or character' describes events, and gives details about the political figure deeds depending on 'actor description'; thus, the use of such function establishes what van Dijk's calls 'self-image'; positive or negative. For Trump, he has no political background. So, he has not been 'attacked' by Clinton. Therefore, his 'defending' function is not highly adopted. Clinton gives the chance to Trump in one way or another to direct 'attacks' on 'person' or 'policy' ground against her. Consequently, her 'defending' function is highly frequent. Therefore, this following section aims at figuring out the LD transfer of information by referring to the mostly utilized content or function SPs across the debate functions. The analysis of SPs is accompanied by illustrative examples for each of the candidates. Finally, overall results for the two candidates' use of SPs are discussed to show the extent to which the SPs are repeated in order to: a) pave the way for the new political party, and $b$ ) enhance affecting people across the debate functions.

Table 5 presents frequencies of occurrence of the content SPs in the three functions of the presidential debate. Some of the CSP in Clinton and Trump's speech are stated along with the previous 'acclaim, attack, and defend' samples. The following table presents the highly employed content SPs, followed by some additional samples, derived from the debate transcript. The candidates' moves are given numbers. Each move begins with the candidates' first name letter.

Table 5

Overall Content and Function SPs across the Presidential Debate

\begin{tabular}{|c|c|c|}
\hline $\begin{array}{r}\begin{array}{r}\text { Presidential function } \\
\text { /Content SPs }\end{array} \\
\end{array}$ & Clinton & Trump \\
\hline Mental Predicators & 119 & 108 \\
\hline Action & 72 & 93 \\
\hline Logical connectors & 106 & 123 \\
\hline Total & 297 & 324 \\
\hline $\begin{array}{l}\text { Presidential } \\
\text { Functions/Function SPs }\end{array}$ & Clinton & Trump \\
\hline Substantives & 288 & 346 \\
\hline Quantifiers & 54 & 115 \\
\hline Possession & 91 & 112 \\
\hline Time & 53 & 60 \\
\hline Total & 486 & 633 \\
\hline
\end{tabular}




\section{Sara El-Daly}

The results displayed in Table 5 show the frequent use of the content and the function SPs across the three presidential functions. Generally, the candidates have used the function SPs more than the content SPs. The most highly used function SPs are substantives, quantifiers, possession, and time. It is obvious that Trump has used the function SPs more than Clinton. Concerning the content SPs, some categories have been used greatly: mental predicators, action, and logical connectors. Generally, Trump has used the content SPs more than Clinton. However, Clinton has employed the content 'mental predicators' more than Trump. Each of the previously mentioned SPs performs a certain political ideological function that affects the readers and/or hearers. The next section presents each of the performed function supported with examples from both Trump's and Clinton's speech.

\subsubsection{Content and Function SPs across the 'Acclaim' Function}

It is notable that Clinton highly use of 'acclaims' depends on mental predicators, logical connectors and action verbs as displayed in Table 6. On the other hand, Trump makes a higher use of 'action verbs' that goes back to his genderlect nature as a male. Some of the 'acclaims' instances are mentioned below

\section{Table 6}

'Acclaim' across Clinton and Trump speech

\begin{tabular}{|l|l|l|}
\hline Content SPs & Clinton & Trump \\
\hline Mental Predictors & 63 & 40 \\
\hline Action Verbs & 35 & 48 \\
\hline $\begin{array}{l}\text { Logical } \\
\text { Connectors }\end{array}$ & 52 & 46 \\
\hline Function SPs & & \\
\hline Substantives & 159 & 151 \\
\hline Quantifiers & 27 & 51 \\
\hline Possession & 57 & 42 \\
\hline Time & 13 & 35 \\
\hline
\end{tabular}

Clinton and Trump 'acclaim' about the future plans more than the comparable personal trait in line $\mathrm{C} 1$ and $\mathrm{T} 1$ using the mental 'think' as a content SPs. However, in line C2 and T2, both of them depend mainly on the function SPs. In C2, she acclaims on the ground of her character when she compares her past deeds serving the country to Trump's. Similarly, Trump 'acclaims' on his past deeds particularly 'education'. The function of 'acclaim' is achieved through using the underlined content and function SPs. 

Samples of Clinton's Acclaim
C 1. I think when we talk
about the Supreme Court, it really raises the central issue in this election, and namely, what kind of country are we going to be?

C 2. And on the day when I was in the Situation Room, monitoring the raid that brought Osama bin Laden to justice, he was hosting the "Celebrity Apprentice." So I'm happy to compare my 30 years of experience, what I've done for this country, trying to help in every way I could, especially kids and families get ahead and stay ahead, with your 30 years, and I'll let the American people make that decision.

\begin{tabular}{llll|}
\hline $\begin{array}{l}\text { Samples of } \\
\text { Acclaim }\end{array}$ & & Trump's \\
\hline T1. We & need a & Supreme \\
\hline
\end{tabular}

Court that in my opinion is going to uphold the Second Amendment, and all amendments, but the Second Amendment, which is under absolute siege. I believe if my opponent should win this race, which I truly don't think will happen, we will have a Second Amendment which will be a very, very small replica of what it is right now. But I feel that it's absolutely important that we uphold, because of the fact that it is under such trauma.

T2. I've visited so many communities. This has been such an incredible education for me, Chris. I've gotten to know so many -- I've developed so many friends over the last year. And they cry when they see what's happened. I pass factories that were thriving 20,25 years ago.

T2a. Well, I think I did a much better job. I built a massive company, a great company, some of the greatest assets anywhere in the world, worth many, many billions of dollars. I started with a $\$ 1$ million loan. I agree with that. 


\section{Sara El-Daly}

Note, underlined words indicate semantic primes. $\mathrm{C}=\mathrm{Clinton}, \mathrm{T}=\mathrm{Trump}$ Further, the two candidates have employed some other linguistic features stated by van Dijk's 'ideological square', Clinton, for example, uses 'actor description' employing such lexemes: happy/adjective; compare/verb, and make a decision to clear-cut phrase creating a negative-other presentation that tends to make him abashed. Similarly, he employs the adjectives: small/adjective, truly/adverb, very/modifier, absolutely/adverb, and important/adjective to create a positive self-image concerning the topics under discussion. Moreover, the evidentiality (van Dijk, 2006) is achieved when: 1) she mentioned her '30years of experience' as a fact and indicator of her political past deeds; and 2) he stated his visits to communities and countries in the last 20 years.

Further, he 'acclaims' on the 'policy' ground describing the past deeds as well as his personal characteristics as a business man, not a politician, as a reply to her comment on the ' 30 years serving the US' which is mentioned in line T2a. 'Actor description' as well as 'hyperbole' is used to describe his great company, in addition to the repetition of the substantive/function SP to glorify his personal trait as a business man.

\subsubsection{Content and Function SPs across the 'Attack' Function}

'Attack' as an important function is employed in this debate mainly by Trump. He resorts to 'attack' Clinton's policy in many instances. When this function is performed, it creates a negative-self presentation that affects the other party's popularity. Given that Clinton's highly performed function is 'acclaim', she sometimes resorts to 'attack' Trump's policy. The two candidates use both the content and the function SPs as shown in Table 7.

\section{Table 7}

'Attack' across Clinton and Trump speech

\begin{tabular}{|l|l|l|}
\hline $\begin{array}{l}\text { Content/Function } \\
\text { SPs }\end{array}$ & Clinton & Trump \\
\hline Mental predicators & 21 & 58 \\
\hline Action Verbs & 17 & 38 \\
\hline $\begin{array}{l}\text { Logical } \\
\text { Connectors }\end{array}$ & 25 & 63 \\
\hline Function SPs & & \\
\hline Substantives & 24 & 166 \\
\hline Quantifiers & 11 & 53 \\
\hline Possessions & 15 & 62 \\
\hline Time & 17 & 24 \\
\hline
\end{tabular}

Clinton 'attacks' the policy represented in Trump's expectations for his future plan in line $\mathrm{C} 3$. The use of 'rhetorical question' at the very 
beginning of her comment denying what he claims about 'using Japan, Korea, and even Saudi Arabia' for nuclear weapons reflects her objection to the planned program using function SP 'the logical concept'/not, and the gerund/hyperbole that renders an exaggerated negative impression/terrifying. The rhetorical question performs an ironical function as rendering the 'rejection/refusing' feeling. Moreover, she 'attacks' his personal characteristics in line C4 that may affect his leadership/presidency creating a negative impression to his voters/negative-other presentation (van Dijk, 2006) by depending on function SPs (after, now, things) and content SPs (heard, saying) and the actor description (big). Finally, the logical concept (not) is mentioned at the end to show that women were not 'attractive' to be assaulted.

\begin{tabular}{|c|c|}
\hline Samples of Clinton's attack & Samples of Trump's attack \\
\hline $\begin{array}{l}\text { C 3. He said, well, if we have } \\
\text { them, why don't we use them, } \\
\text { which I think is terrifying. } \\
\text { But here's the deal. The } \\
\text { bottom line on nuclear } \\
\text { weapons is that when the } \\
\text { president gives the order, it } \\
\text { must be followed. There's } \\
\text { about four minutes between } \\
\text { the order being given and the } \\
\text { people responsible for } \\
\text { launching nuclear weapons to } \\
\text { do so. } \\
\text { C 4. At the last debate, we } \\
\text { heard Donald talking about } \\
\text { what he did to women. And } \\
\text { after that, a number of women } \\
\text { have come forward saying } \\
\text { that's exactly what he did to } \\
\text { them. Now, what was his } \\
\text { response? Well, he held a } \\
\text { number of big rallies where } \\
\text { he said that he could not } \\
\text { possibly have done those } \\
\text { things to those women } \\
\text { because they were not } \\
\text { attractive enough for them to } \\
\text { be assaulted. }\end{array}$ & $\begin{array}{l}\text { T 3. Well, I think it's terrible. } \\
\text { If you go with what Hillary is } \\
\text { saying, in the ninth month, } \\
\text { you can take the baby and rip } \\
\text { the baby out of the womb of } \\
\text { the mother just prior to the } \\
\text { birth of the baby. Now, you } \\
\text { can say that that's OK and } \\
\text { Hillary can say that that's OK. } \\
\text { But it's not OK with me, } \\
\text { because...... }\end{array}$ \\
\hline
\end{tabular}




\section{Sara El-Daly}

As for Trump, Trump's most performed and adopted function is 'attack'. He attacks both the political and social deeds of the past as well as the future planned policy Clinton displayed for the American society. Additionally, he attacks the 'personal' characteristics of her as a 'political' figure as reflected in many issues; such as his reaction towards the lateterm partial birth abortion. From the very beginning he employs the actor description/the adjective 'terrible', the content SP action verb/go with, and the content SP speech/say to reflect the negative side and his refusal to the present policy at that time (i.e. Obama presidency) and/or to what she is planning to have using the function SP logical concept/not and time determiner/now.

Moreover, the 'attack' strategy on the 'character' and 'policy' grounds is represented in the following example. Clinton in C5 claims that 'the next president is a puppet' that is regarded as an 'ironical' reference indicating childish and irresponsible behavior. She depends on the similarity linguistic device 'as'. In addition, she, in C7 uses SPs to clarify that he 'will not admit' that the 'coming president' is 'a puppet'. 'No puppet' is his reply to the claimed offensive simile, and he directs the same simile to her 'insulting her' in T7. These moves are in the form of 'adjacency pairs', as if it is a dialogue between the two candidates and not a debate that is controlled by certain rules.

T 5: ... from everything I see, has no respect for this person.

C 5: Well, that's because he'd rather have a puppet as president of the United States.

T 6TRUMP: No puppet. No puppet.

C6: And it's pretty clear...

T 7: You're the puppet!

C7: It's pretty clear you won't admit...

T8: No, you're the puppet.

The rules of conduct (van Eemeren and Grootendorst, 2004, p. 175) which achieve what is known as strategic maneuvering are not achieved when interrupting each other, and not following the rules of the debate. The rules of conduct are some rules set by the two parties to ensure a coherent and well-established conversation. When interrupting others, firstly, the freedom rule is where the conversation parties should help each other to advance a standpoint and never prevent discussion is 
violated. Secondly, the relevance rule is where standpoints may not be defended by non-argumentation or irrelevant argumentation. And finally, the language rule is where parties may not use any formulations that are insufficiently clear or confusingly ambiguous, and they may not deliberately misinterpret the other party's formulation (van Eemeren and Grootendorst, 2004, p. 187-190). The previous example shows a violation of these three rules. On the contextual level, this text is taken from Trump's reply to the issue of ISIS and the relations between America and Russia. Wallace (the debate mediator) tries to interrupt him with 'wait, but...' Trump takes the floor to continue his series of sarcastic attacks against Clinton. Analytically, Wallace's 'self-select' (Sacks, Schegloff, and Jefferson, 1974, p. 700-704) is to stop Trump's attack against Clinton concerning the Russian issues.

\subsection{Content and Function SPs across the 'Defending' Function}

Further, the use of SPs helps Clinton to employ the 'defending' function responding to Trump's 'attacks' either on her policy or her personal characteristics.

\section{Table 8}

'Defending' across Clinton and Trump Speech

\begin{tabular}{|l|l|l|}
\hline $\begin{array}{l}\text { Content/Function } \\
\text { SPs }\end{array}$ & Clinton & Trump \\
\hline Mental predicators & 35 & 10 \\
\hline Action Verbs & 20 & 7 \\
\hline $\begin{array}{l}\text { Logical } \\
\text { Connectors }\end{array}$ & 29 & 14 \\
\hline Function SPs & & \\
\hline Substantives & 105 & 29 \\
\hline Quantifiers & 16 & 11 \\
\hline Possessions & 19 & 8 \\
\hline Time & 23 & 1 \\
\hline
\end{tabular}

In line C8, she tries to repair herself-image after Trump's words about the Second Amendment when he attacks her employing negativerepresentation strategy (van Dijk, 2004) depending on actor-description, the adjectives/upset and angry, repetition of the semantic prime 'very' in T9. This repetition renders the exaggeration meaning (hyperbole). Clinton's attempts to 'defend' are always interrupted with his interventions; therefore when she starts to reply, he interrupts with 'wrong' as in Trump's attack/T 12. In line C9, she tries to respond in the same way he is responding, creating a negative-other presentation depending on the semantic primes; determiner/this; substantives/I; 


\section{Sara El-Daly}

augmenter/very; and the actor description with these adjectives/cavalier and casual. Therefore, he attacks by the intervention 'wrong'.

\begin{tabular}{|c|c|}
\hline Trump Attack/policy & Clinton's defending /policy \\
\hline $\begin{array}{l}\text { T 9. But Hillary was } \\
\text { extremely upset, extremely } \\
\text { angry. And people that } \\
\text { believe in the Second } \\
\text { Amendment and believe in it } \\
\text { very strongly were very } \\
\text { upset with what she had to } \\
\text { say. }\end{array}$ & $\begin{array}{l}\text { C 8. But there's no doubt that } \\
\text { I respect the Second } \\
\text { Amendment, that I also } \\
\text { believe there's an individual } \\
\text { right to bear arms. That is } \\
\text { not in conflict with sensible, } \\
\text { commonsense regulation. }\end{array}$ \\
\hline Trump Attack/Character & $\begin{array}{l}\text { Clinton } \\
\text { Defending/Character } \\
\text { policy }\end{array}$ \\
\hline $\begin{array}{l}\text { T 10. She doesn't like Putin } \\
\text { because Putin has } \\
\text { outsmarted her at every step } \\
\text { of the way.... } \\
\text { T 11. And she always will } \\
\text { be. } \\
\text { T 12. Wrong }\end{array}$ & $\begin{array}{l}\text { C } 9 \text { I -- I find it ironic that } \\
\text { he's raising nuclear weapons. } \\
\text { This is a person who has } \\
\text { been very cavalier, even } \\
\text { casual about the use of } \\
\text { nuclear weapons. He's... }\end{array}$ \\
\hline
\end{tabular}

Trump has no political background; she rarely 'attacks' him on the ground of 'policy'. As a result, Wallace asks (in the form of attack) him a question and Trump defends himself to self repair his image employing content and function SPs.

\begin{tabular}{|c|c|}
\hline T. Defense/character & Wallace Attack/character \\
\hline $\begin{array}{l}\text { T. } 13 \text { Well, first of all, those } \\
\text { stories have been largely } \\
\text { debunked. Those people -- I } \\
\text { don't know those people. I } \\
\text { have a feeling how they } \\
\text { came. I believe it was her } \\
\text { campaign that did it. Just like } \\
\text { if you look at what came out } \\
\text { today on the clips where I } \\
\text { was wondering what } \\
\text { happened with my rally in } \\
\text { Chicago and other rallies }\end{array}$ & $\begin{array}{l}\text { Wallace: Mr. Trump, at the } \\
\text { last debate, you said your } \\
\text { talk about grabbing women } \\
\text { was just that, talk, and that } \\
\text { you'd never actually done it. } \\
\text { And since then, as we all } \\
\text { know, nine women have } \\
\text { come forward and have said } \\
\text { that you either groped them } \\
\text { or kissed them without their } \\
\text { consent. }\end{array}$ \\
\hline
\end{tabular}


where we had such violence?

She's the one and Obama that caused the violence. They hired people -- they paid them $\$ 1,500$, and they're on tape saying be violent, cause fights, $\underline{\text { do }}$ bad things....

Trump depends on 'actor description' and 'evidentiality' that appear in the defense of this issue. He states that Clinton's campaign has prepared all these false claims concerning his relations to women. Semantically, the evaluative adjective 'bad', logical concept 'not', and mental predicate 'know' are used. In his trial to defend himself, he presents her negatively and, accordingly, 'attacks' her. He accuses her campaign of preparing these 'stories'. He completely denies his responsibility, changes the topic and people's direction to another issue that condemns her.

It is notable that Clinton has followed the 'activist style' (Napierala, 2014, p. 129) that shows the 'leadership style' because she focuses on two main threads: past achieved actions as a result of achieving some functions rather than others, and the future initiatives for the upcoming next plans. This style is reflected in her use of 'acclaim' for policy across the debate moves. Conversely, Trump may be described as following the 'passive style', as he reacts to the past deeds of the late policy or to Clinton's previous achievements. This is reflected in his continuous preference to employ 'attacks' rather than 'acclaims' on the ground of policy.

Moreover, both of the two candidates employ two different image strategies; Clinton focuses on 'personification' strategy. She tries to embody the role of a 'family woman' when discussing some certain important issues such as woman abortion, guns, and giving middle class families more opportunities/economic issue. Moreover, she employs the 'identification' strategy as she continues displaying her beliefs concerning the political issues: building borders and advanced manufacturing for economy growing. Similarly, Trump has focused on the 'personification' and 'identification' strategies. He represents his 30 years of work as a business man building massive companies and hotels around the world (i.e. Trump Foundation). Additionally, he identifies what he believes in, when he insists on building boarders, renegotiating trade deals/free trade deals, and ISIS situation.

Concerning the verbal strategies (Napierala, 2014) the candidates use in this debate, Clinton has used 'emphasize accomplishments'. This is 
reflected in her choice of 'acclaims' as she talks more about her remarkable achievements of the past and through 'defending' the 'attacks' of Trump. This strategy shows the candidate's desire to be re-elected for the political position. And she uses 'better safe spontaneous', as she sticks with true and tried campaign (P. 129). In this way she follows the standard answers to the given questions. Trump uses also 'better safe than spontaneous' strategy but following another tool, that is to respond not with an answer but with an 'attack', the reason beyond repeating attacks. Moreover, his second preferred strategy is 'simplify'; to use short sentences, repetitions, and iconic examples to facilitate the process of transferring the meaning to the voters (listeners, viewers, and audiences). In this sense, the role of semantic primes appears in helping to smooth the cross-cultural communication.

\subsection{Results of $L D$ across the Presidential Debate Strategies}

\subsubsection{Clinton's and Trump's Content and Function SPs}

The content SPs frequency of use is represented in Figure 1. Given that content SPs are the main lexicons that convey the meaning, the two candidates show a high degree of similarity employing the same SPs. It is notable that Trump uses content SPs more than Clinton.

\section{Figure 1}

\section{Content SPs across the Three Political Functions}

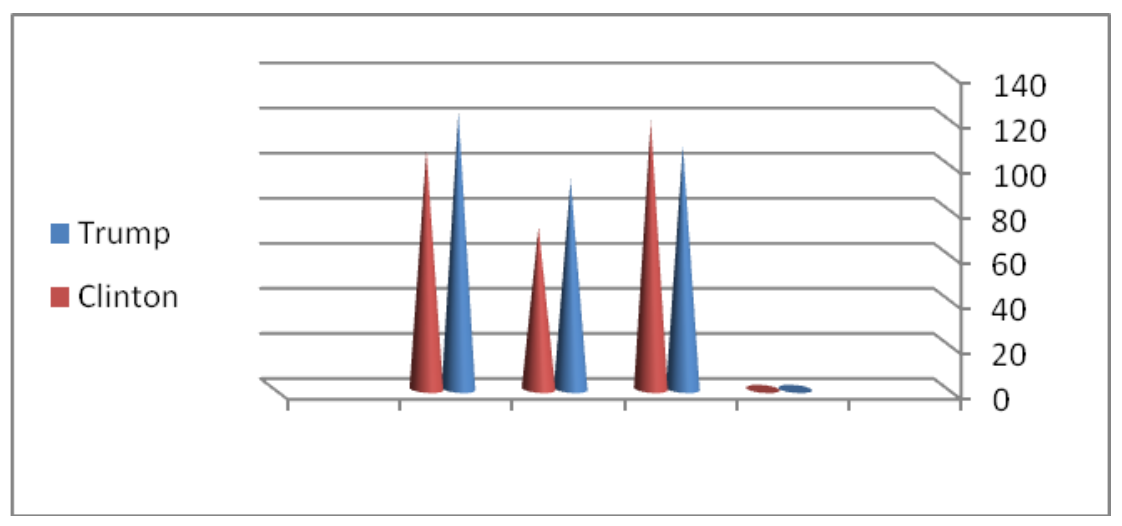

Semantically, Clinton used 'think, know, and see' as she needs to raise the cognitive ability of her voters, even when she resorts to 'emotional verb/feel' two times, she was trying to affect the listeners. The 'think and know' verbs belong to 'epistemic mood of verbs' (Krawczak and Fabiszak, 2011). Similarly, Trump used this category of verbs more than Clinton. The use of the 'epistemic verbs' reflects the candidates' tendency to share their mental status with the world that creates a sense of negotiation concerning the topic under discussion. Pragmatically, the use of mental verbs belongs to the 'expressive speech act category' (Searle, 1975, p. 17- 
19). In this category, the speaker expresses his/her feelings to the listener/reader. So, the two appeals of Aristotle's canons 'logos and pathos' are used in the text. Finally, the use of 'logical concepts', particularly 'not', reflects her ability to claim, then come back to modify/correct her speech.

\section{Figure 2}

\section{Function SPs across the Three Political Functions}

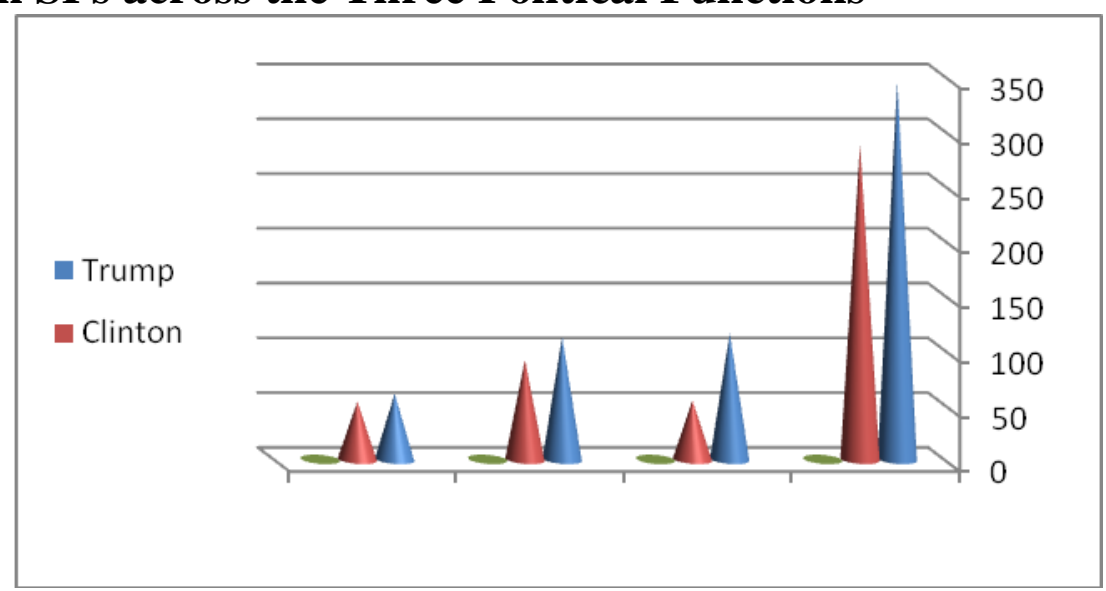

It is obvious from the previous figure that Clinton \& Trump have employed the 'substantives/FSP' category more than the other primes. This category includes the simple words (I/you/people). The highly employed SP in this segment is 'I' in their contributions. Trump used the term more than Clinton. For Clinton, she resorted to the use of the personal pronoun 'I' that preceded the semantic primes/mental verbs 'see and feel'. Moreover, she used the pronoun before 'desire or voluntary verbs'; 'looking forward to' and 'desire'. In this sense, she expresses her willingness creating a new beginning to the American people. As for Trump, he made a variety of 'I' sentences. He uses the pronoun before different verbs that rendered different meanings; mental (epistemic) verbs; think, feel, and believe; action verbs; going to appoint; and representative verbs; represent and name (the representative speech act) (Searle, 1976, p. 10) to represent a factor reality.

Given the nature of the political debate, persuasion is the ultimate aim of the candidates. Therefore, they may resort to various techniques to affect their audiences. The use of complete sentence with the subject 'I' and the categorized verbs serve the function of presenting the ideas logically to the audiences. The second highly use of substantives is the prime 'people'. They have almost used the term equally. By the use of 'the American people', they try to affect them. Therefore, resorting to 'pathos', as one of 'Aristotle's' canons to achieve persuasion, is the candidates' second 
performed discourse mapping strategy. With regard to the contextual setting, the candidate needs to persuade people to vote for him/her.

With regard to the aim of persuasion in the political debate, Trump had used the 'support' more than Clinton. 'Support' here refers to the use of some words and modifiers to affect the listeners (Toulmin, 2003, p. 103104). Trump used augmenters/intensifiers/quantifiers greatly; his use of these functional SPs was not on the base of presenting new 'claim'. It was a result of repeating the augmenter and intensifier more than one time. This repetition is due to the nature of spoken language and/or the weakorganization of his discourse.

The content words are those words that carry the meaning, while the function words are those that have no relation to the intensity of the speech or the written text. In this study lexical density is measured in light of the notion of semantic primes, a way to see how the lexical words (content words) helped to transfer the meaning to any culture in the easiest manner. Generally, both the two candidates employ the function words (the grammatical forms) more than the content words (the carriers of meaning). The content words are supposed to transfer the meaning to those who are watching the 'televised' political debate. However, the candidates did convey the meaning depending on the 'the use of grammar'. The dominant functional SP is 'substantives' category. The use of 'you' is to direct the 'attack' to the other speaker.

Generally, there were many instances of illegal contributions either by Clinton or Trump. Concerning the instances of interventions, Wallace tried to control the situation and the given time. Such interruptions or irrelevant contributions were employed because, firstly, in case the two candidates were confronted with facts/realities and cannot reply or justify them clearly. Secondly, conversations are displaying various number of situations where many individuals (i.e. identities are shown, gender differences, religious differences, and ethnic variations) are involved. Therefore, in context-free situations (depending on initiated topics), no systematic model of turn-taking or set of controlling rules would help to overwhelm the conversations (Sacks, Schegloff, and Jefferson, 1974, p. 8 ). Given the institutional context and pre-determined rule of timecontrol, the two candidates should have followed this rule.

Werizbicka (2003, p. 453) states that in any language, there are a stone of words that creates the basis for cross-cultural understanding. And it is obvious that the two candidates' use of 'semantic primes/function words' creates a cross-understanding of empty messages with almost insufficient information. The 'information packaging' is achieved by lexical density 
(Johansson, 2008, P: 65). And it seems that this debate is not 'lexical dense', as the content words are less than the function words. This debate displays insufficient information display, due to the loss of information packaging.

\subsubsection{Discussion and Findings}

The results of the study may be interpreted in light of the differences between written and spoken discourse. Paltridge (2006, p. 13-15) states that written discourse is more lexical dense than spoken discourse, and, concerning 'grammatical intricacy', he adds that written discourse is more grammatically intricate than spoken discourse. The findings of the previous analysis- with regard to semantic primes- show that the 'televised/spoken' political debate focuses on the function words. So, it is not a 'lexical dense' but 'a grammatical intricate'. Given that it is a spoken discourse, it shall not be grammatically complex. Thus, the image of the 'given debate' is not clear. This image reflects the 'identity' of the speakers who are responsible for producing such speech. Accordingly, their ideologies, the shared framework of mental models that a group of individuals possess, and its cognitive function of structuring political knowledge (Knight, 2006, P. 22) are not adequately established.

The results of this study seem to support what Chilton (2004) states about the 'frame based knowledge' and 'the metaphorical mapping' (p. 61). The great frequency of function SPs does not help constructing such a map in the other's mind that leads to creating an empty atmosphere for knowledge structure. The general use of function SPs, and particularly prepositions (time/space deictic expressions), pronouns (substantives) creates what Chilton refers to as a 'frame-based knowledge' (Chilton, p.61) which is the superficial cover with no deep constructions formed by content SPs. Moreover, the pronominal choice of 'I' refers to the speaker's cognitive ability to reinforce his relation to the hearers and/or readers. In other words, the pronoun 'I' selection is used to "gain people's allegiance" (Boyd, 2013, p.305). In this sense, Trump is trying to affect the people selecting him in the last presidential debate.

Based on the great use of function SPs, the notion of 'manipulation' is achieved as the candidates tend to convey certain messages to the world around them. Manipulation based on the processes of 'mind control' (Rashidi and Souzandehfar, 2010, p. 65). The semantic analysis shows the nature information is conveyed by and the candidates' preferable lexicons to affect others. The cognitive ability appears here in interpreting the conveyed messages (in this study, empty ones) in light of the ideology 


\section{Sara El-Daly}

of the speakers. This reflects that the two candidates go hand in hand to convey similar messages though their different social ideological representations.

Moreover, the linguistic performances the candidates' prefer enhance the notion of 'information warfare/IW'. IW is defined as "actions taken to achieve information superiority by affecting adversary information, information-based processes, information systems, and computer-based networks while defending one's own information, information-based processes, information systems, and computer-based networks" (Haeni, 1997, p. 3). The results of the analysis show that 'information warfare is not only about the acquisition of information; it is also possible to spread information, real or fictitious' (Haeni, 1997, p. 6). Given that it is a televised political debate, it belongs to the kind of warfare 'soft war'. "The aim is not directly to achieve information superiority, but to manipulate the enemy (or one's own population) with false or adapted information. TV (televised political debates) is used to shape the other Nation's will, and to change the view of reality" (Haeni, 1997, P. 11). Therefore, the 'apparent' use of semantic primes and preference use of the 'function words' reflect the hidden purpose that is not only loss of 'information packaging', but also 'fictitious fake adopted information'. Thus, the whole speech may be seen as a 'pseudo display'. This display tends to transfer focusing on semantic primes- false claims to the whole world.

\section{Conclusion}

The analysis of the last presidential debate reveals that both the two candidates have employed the semantic primes greatly in their speech, given that the differences and/or similarities between them serve the function of conveying particular information across the performed activities. The functions of the political debate have been achieved as the two candidates have used the three debate functions in a different manner. Therefore, the aim of the study to examine the use of semantic primes in the last presidential debate between Hillary Clinton and Donald Trump is fulfilled. Moreover, the paper presents the notion of 'information intensity' through 'lexical density' after categorizing the semantic primes. The content of the communicative message is reflected through the ratio of content to function words. The study reveals that the frequencies of the 'function words'-according to semantic primes- are more than the content words, which indicates the importance of 'information packaging' that becomes insufficient, due to the less use of carriers of meaning 'content words'. Given that the debates-to a great extent- are not spontaneous and are pre-prepared by the campaign, it may be concluded that they are 
intended to convey messages with incomplete set of information. Regarding the two presidents' different employed strategies, Clinton has shown her 'activist' political manner across the debate turns due to her past political experience, while Trump's 'passive' political manner is reflected in his continuous repetitions and dependence on 'identification' strategies, reflecting his experience that lacks the political background. In light of the above claims, it may be concluded that the political figures reflect: A) realities about their lives (i.e. concerning their experiences); B) trained behavior on how to enact on stage using the falsified/true facts; and C) cross-cultural awareness of the semantic primes' that help in understanding the communicative messages' contents. 


\section{References}

Benoit, W. and Hansen, G. (2004). Presidential Debate Watching, Issue Knowledge, Character Evaluation, and Vote choice. Human Communication Research.Vol. 30 (1). PP. 121-144.

Boyd, M. (2013). Reframing the American Dream: Conceptual metaphor and personal pronouns in the 2008 US presidential debates. In Cap, P. and Okulska, U. (Eds.). Analyzing Genres in Political Communication, John Benjamins Publishing Company. Amsterdam/Philadelphia.

Chilton, P. (2004). Analyzing Political Discourse: Theory and Practice. Routledge: London and New York.

Eemeren, V. \& Grootendorst, R. (2004). A systematic theory of argumentation: The pragma-dialectical approach. Cambridge: Cambridge University Press.

Goddard, C. (1996). 'The Social Emotions' of Malay 'Bahasa Melayu'. Journal $\begin{array}{llll}\text { of } & \text { Pragmatics } & 27 & 183-201\end{array}$

https://s3.amazonaws.com/academia.edu.documents/34456793/Goddard _CulturalValues_ScriptsMalay_1997.

Goddard, C. (2006). Ethnopragmatics: a new Paradigm. In C. Goddard (Ed.) Ethnographics: Understanding Discourse in Culture Context. (PP. 1-30). Berline: Mouton de Gruyter.

Goddard, C. (2010). Semantic molecules and Semantic Complexity: with special reference to Environmental' moelclues. Review of Cognitive Linguistics. 8 (1), 123-155.

Goddard, C. and Wierzbicka, A. (2007). Semantic Primes and Cultural Scripts in Language Learning and Intercultural Communication. In Garypalmer and Farzad Sharifian (eds.), Applied Cultural Linguistics: implications for Second Language Learning and inter-cultural Communication. Amestrdam: Jhon Benjamin, 105-124.

Haeni, R. (1997). Information Warefare: an Introduction. The George Washington University. Retrieved from http://www.worldinwar.eu/wp

Johnssan, V. (2008). Lexical Diversity and Lexical Density in Speech and Writing: A Developmental Perspective. Lund: Lund University. Working Papers 53, 61-7.

Johnstone, B. (2002). Discourse Analysis. Blackwell Publishers: Malden, Massachusetts.

Joo Yoon, K. (2001). The Semantic Primes 'this' in Korean. Proceedings of the 2001 Conference of the Australian Linguistic Society. Retrieved from http://www.als.asn.au/proceedings/als2001/yoon.pdf

Journals.lub.lu.se/index.php/LWPL/article/download/22

Kalisz, R. (1993). Different Cultures, Different Languages, and Different Speech Acts Revisited. Poznan, Papers and Studies in Contrastive Linguistics, vol. XXVII. $\quad$ Retrieved from http://wa.amu.edu.pl/psicl/files/27/07Kalisz.pdf.

Knight, K. (2006). Transformations of the concept of ideology in the twentieth Century. American Political Science Review. Vol. 100, N. 4. Retrieved 
from

http://citeseerx.ist.psu.edu/viewdoc/download?doi=10.1.1.611.335\&rep= rep1\&type $=$ pdf

Krawczak, K. and Fabiszak, M. (2011). Cognition verbs in Polish, their construal and complement semantics. Paper presented at the $3^{\text {rd }}$ Conference of the Scandinavian Association for language and Cognition,

http://wa.amu.edu.pl/wa/files/Cognition\%20Verb

Copenhagen.

Mateo, Mendaza (2016). 'The Search for Old English Semantic Primes: the Case of Happen." Nordic Journal of English Studies, Vol. 15 (1): PP. 7199.

Retrieved

from

ojs.ub.gu.se/ojs/index.php/njes/article/download/3442/2886

Napierala, K. (2014). The Verbal Strategies in the Obama-McCain Debates. The Criterion; An International Journal in English, vol.5, (3), 126-137. Retrieved from http://www.the-criterion.com/V5/n3/Karolina.pdf

Nozickova, Tereza. (2013). The 2012 U.S. Presidential Debates. A Discourse Analysis. Tomas Bata University in Zlin faculty of Humanities.

Paltridge, B. (2006). Discourse Analysis: An Introduction. London: Continuum Discourse Series.

Prace, Z. (2013). The 2012 U.S. Presidential Debates: A Discourse Analysis. Bachelor theses. Thomas Bata University in Zlin Faculty of Humanities.

Rashidi, N. and Souzandehfar, M. (2010). A Critical Discourse Analysis of the Debates between Republicans and Democrats over the Continuation of War in IRAQ. Retrieved from http://www.uab.ro/jolie/2010/4 rashidisouzandehfar.pdf

Sacks, H., Schegloff, E., and Jefferson, G. (1974). A simplest Systematic for the organization Of Turn-Taking for Conversation. Language, Vol. 50, N. 4, PP. 696-735.

*Sacks, H., Schegloff, E., and Jefferson, G. (1978). A simplest Systematic for the organization Of Turn-Taking for Conversation. Reprinted from: Studies in The Organization of Conversational Interaction. Academic Press, Inc, NewYork, San Francisco, London.

Savoy, J. (2016). Trump's and Clinton's Style and Rhetoric during the 2016 Presidential Election. Retrieved from http://www.researchgate.net/publication/311588853.

Searle, J. (1975). Indirect speech Acts. In P. Cole and J. Morgan (Eds.), Syntax and Semantics. Vol.3: speech acts. New York: Academic Press.

Searle, J. (1976). A Classification of Illocutionary Acts. Language in Society, Vol.5, N. 1.

Swan, K. (2013). Borrowing the Essentials: A Diachronic Study of the Semantic Primes of the Modern English. A Thesis Submitted to the Faculty of Brigham Young University. Retrieved from https://scholarsarchive.byu.edu/cgi/viewcontent.cgi?article=5248\&conte $\underline{\mathrm{xt}=\mathrm{etd}}$ 


\section{Sara El-Daly}

Toulmin, E. (2003). The Uses of Argument. Cambridge: Cambridge university press.

Van Dijk, Teun. (2002). Political Discourse and Ideology. University of Amesterdam.

Van Dijk, Teun. (2004). Discourse, Knowledge and Ideology: Reformulating Old Questions and proposing some new Solutions. In Martin Putz, JoAnne Neff and Van Dijk (eds.) Communicating ideologies. Multidisciplinary Perspectives on Language, Discourse, and Social Practice. Retrieved from https://www.academia.edu/4261377/

Van Dijk, Teun. (2005). Contextual knowledge management in Discourse production: ACPA perspective published in Ruth Wodak and Paul Chilton (Eds.), A New Agenda in critical Discourse Analysis: Amesterdam: Benjamins.

Van Dijk, Teun. (2006). Discourse, context and cognition. Discourse Studies. Vol. 8(1): 159-177.

Werizbicka, A. (1985). 'Different Cultures, different Languages, and different speech acts: Polish VS English'. Journal of Pragmatics vol. 9, pp (145178).

Wierzbicka, A. (1996). Semantic Primes and Universals. Oxford: Oxford University Press.

Wierzbicka, A. (2003). Cross-cultural Pragmatics. The semantics of Human Interaction. Mouton de Cruyter: Berlin.

Werizbicka, A. (2010). Cultural Scripts of Intercultural Communication. In Trosborg, A. (Ed). Pragmatics across Cultures. Walter de Gruyter Gmbtl and Co.KG, Berlin, New York. 
